\title{
The Emerging Potential and Perspectives of Induced Pluripotent Stem Cells (iPSCs)
}

\section{Claudia Compagnucci*}

Unit of Neuromuscular and Neurodegenerative Disorders; Laboratory of Molecular Medicine, Department of Neurosciences; Bambino Gesù Children's Research Hospital, IRCCS, Piazza S. Onofrio, 4, 00165 Rome, Italy

Induced pluripotent stem cells (iPSCs) are stem cells reprogrammed from adult somatic cells of different embryonic origin: in fact they have been obtained from the ectoderm [i.e., keratinocytes and neural cells, [1-3], the endoderm [i.e., hepatocytes [4], and the mesoderm [i.e., fibroblasts, Takahashi and Yamanaka and Lancaster et al. $[5,6]$. The great potential offered by these cells is that they bias any ethical concern dealing with embryonic stem cells as they are of somatic origin and they pave the way to future translational studies where these cells, properly treated and cultured, can allow self-transplantation. These are additional issues that justify the endeavor to understand the biological features of iPSCs with the aim of manipulating them in vitro in order to perform effective drug screenings and in the future of therapeutic transplantation. My questions are: Are the in vitro conditions commonly used for line cells suitable for iPSCs? Do iPSCs require an environment closer to the physiological stem cell niche?

In light of these questions, it is widely accepted that the knowledge necessary to recreate the correct stem cell environments in vitro is indubitably missing, and this impedes understanding the bases of stem cell biology or developing them for therapeutic purposes and regenerative medicine. Unfortunately, the molecular factors acting in the environment of organ stem cells are mostly unknown and, the network of signaling pathways controlling self-renewal versus differentiation are poorly understood as well. Therefore, stem cells cannot account on the optimal environment in vitro and this is a relevant obstacle that needs to be overcome before considering iPSCs for therapeutic transplantations. Noteworthy, the molecular and cellular mechanisms leading to celldifferentiation are starting to be unveiled and carefully characterized. Recently, the work by Lancaster et al. (2013) demonstrates that proper handling of iPSCs in vitro allows the development of threedimensional cerebral organoids resembling features of a real brain. Many human diseases suffer from the poor availability of tissues that can be studied, as for neurological diseases. In these situations, iPSCs offer the possibility to study the cell type of interest, neurons or glia, as these cell types can be obtained in vitro from properly manipulated iPSCs. Importantly, the cerebral organoid can be considered as a threedimensional model where glial cells and neurons interact and together shape the architecture of a simplified brain, thus offering great hopes for future applications of iPSCs to model neurological diseases, which at present could not be studied for the difficulties in gathering tissue samples. Moreover, iPSCs technology offer a valuable therapeutic option for any genetic disease, considering that the iPSCs, if properly obtained, cultured and handled can be genetically corrected in vitro prior to transplantation into tissues in need of repair.

Despite (in 2012) the Nobel prize in Physiology or Medicine has been awarded to Sir John B. Gurdon and Shinya Yamanaka for the studies leading to iPSC technology and, despite many top-journals have published iPSC studies as cellular models recapitulating the features of the human pathology (which affected the individual from whom the somatic cells were obtained before reprogramming), the funding for studies proposing the generation of iPSC-disease modeling often raises, in the reviewers, the fear that the project is too ambitious or that the possibility to obtain iPSCs and the derived model of the disease of interest is not faithful. The consequence of this conservative attitude is that few laboratories can afford to pay for the expensive materials that the iPSCs require. This, on one side, allows well-funded laboratories to work on iPSCs, but, on the other side, it slows down the understanding of iPSC biology and the pace of new discoveries in the field of in vitro disease modeling. For the future I have one hope and one prediction. The hope is that more and more laboratories can afford to work on iPSCs in order to properly expand knowledge on the iPSC biology. The prediction is that with the increasing confidence that the scientific community will rely on iPSC technology, more and more companies will offer materials and tools for the development of iPSC technology, thus leading to acompetitive market that will allow to lessen the costs of the iPSC materials. The underlying prospective behind iPSC technology is that it can allow the generation of human disease models as well as providing different cell types for high-throughput cellular drug screening and potentially turn out to be a resource for regenerative medicine. In this scenario of potentials that iPSC technology may offer, it is of great importance to promote knowledge on iPSC biology and the development of standardized tools for iPSC differentiation into different cell types. Isn't it?

\section{References}

1. Aasen T, Raya A, Barrero MJ, Garreta E, Consiglio A, et al. (2008) Efficient and rapid generation of induced pluripotent stem cells from human keratinocytes. Nat Biotechnol 26: 1276-1284.

2. Kim D, Kim CH, Moon JI, Chung YG, Chang MY, et al. (2009) Generation of human induced pluripotent stem cells by direct delivery of reprogramming proteins. Cell Stem Cell 4: 472-476.

3. Kim JB, Zaehres H, Wu G, Gentile L, Ko K, et al. (2008) Pluripotent stem cells induced from adult neural stem cells by reprogramming with two factors. Nature 454: 646-650.

4. Liu H, Ye Z, Kim Y, Sharkis S, Jang YY (2010) Generation of endoderm-derived human induced pluripotent stem cells from primary hepatocytes. Hepatology 51: 1810-1819.

5. Takahashi K, Yamanaka S (2006) Induction of pluripotent stem cells from mouse embryonic and adult fibroblast cultures by defined factors. Cell 126: 663-676.

6. Lancaster MA, Renner M, Martin CA, Wenzel D, Bicknell LS, et al. (2013) Cerebral organoids model human brain development and microcephaly. Nature 501: 373-379.

${ }^{*}$ Corresponding author: Claudia Compagnucci, Unit of Neuromuscular and Neurodegenerative Disorders; Laboratory of Molecular Medicine, Department of Neurosciences; Bambino Gesù Children's Research Hospital, IRCCS, Piazza S. Onofrio, 4, 00165 Rome, Italy; Tel: 0039 3493729071; E-mail: claudia.compagnucci@googlemail.com

Received February 25, 2014; Accepted February 26, 2014; Published March 04, 2014

Citation: Compagnucci C (2014) The Emerging Potential and Perspectives of Induced Pluripotent Stem Cells (iPSCs) J Biomol Res Ther 3: e132. doi: 10.4172/2167-7956.1000e132

Copyright: () 2014 Compagnucci C. This is an open-access article distributed under the terms of the Creative Commons Attribution License, which permits unrestricted use, distribution, and reproduction in any medium, provided the original author and source are credited. 